\title{
The Role of Cohesion Policy Funds in Decreasing the Health Gaps Measured by the EURO-HEALTHY Population Health Index
}

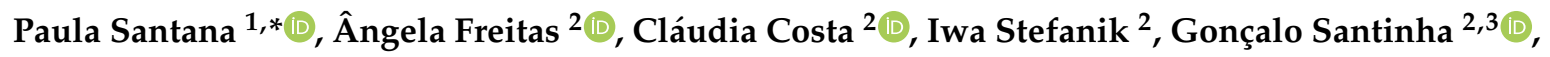 \\ Thomas Krafft ${ }^{4,5}$ and Eva Pilot ${ }^{4,5}$ (D) \\ 1 Department of Geography and Tourism, Faculty of Arts and Humanities, University of Coimbra, 3004-530 \\ Coimbra, Portugal \\ 2 Centre of Studies in Geography and Spatial Planning (CEGOT), University of Coimbra, 3004-530 Coimbra, \\ Portugal; angela.freitas@uc.pt (Â.F.); claudiampcosta@uc.pt (C.C.); iwastefanik@gmail.com (I.S.); \\ g.santinha@ua.pt (G.S.) \\ 3 Department of Social, Political and Territorial Sciences; Governance, Competitiveness and Public Policies \\ Research Unit (GOVCOPP), University of Aveiro, 3810-193 Aveiro, Portugal \\ 4 Department of Health, Ethics and Society, Faculty of Health, Medicine and Society, Maastricht University, \\ P.O. Box 616, 6200 MD Maastricht, The Netherlands; thomas.krafft@maastrichtuniversity.nl (T.K.); \\ eva.pilot@maastrichtuniversity.nl (E.P.) \\ 5 Maastricht Centre for Global Health, Maastricht University, P.O. Box 616, 6200 MD Maastricht, \\ The Netherlands \\ * Correspondence: paulasantana@uc.pt
}

Received: 4 December 2019; Accepted: 25 February 2020; Published: 29 February 2020

\begin{abstract}
Social, economic, and environmental differences across the European Union significantly affect opportunities to move forward in achieving greater equity in health. Cohesion Policy (CP) funds can contribute positively through investments in the main determinants of health. The aim of this study is to analyze to what extent the planned investments for 2014-2020 are addressing the regional health gaps, in light of the population health index (PHI), a multidimensional measure developed by the EURO-HEALTHY project. The operational programs of all regions were analyzed, namely, the CP planned investments by field of intervention. Analysis of variance was performed to examine whether the regional scores in the PHI dimensions were statistically different across regions with different levels of development (measured by gross domestic product (GDP)). Results show that $98 \%$ of regions with worse performances on the PHI are less developed regions. Overall, all regions present planned investments in intervention fields linked to dimensions appraised within the PHI (e.g., employment, income, education, pollution). Yet, more needs to be done to focus regional investments in health determinants where regions still lag behind. The PHI has the potential to inform future $\mathrm{CP}$ restructuring, providing evidence to extend the current eligibility criteria to other dimensions beyond the GDP.
\end{abstract}

Keywords: European Union; regional health inequalities; cohesion policy funds; determinants of health; population health index; less developed regions; intervention field

\section{Introduction}

The factors that are causing differences in the social, economic, and environmental conditions in the European Union (EU) are also leading to health inequalities that, in turn, undermine efforts to achieve effective social and spatial cohesion [1-4]. Health became an evolving concept since the landmark World Health Organization (WHO) definition in 1948, which stated that "health is a 
state of complete physical, mental, and social well-being and not merely the absence of disease or infirmity". Concurrent to the discussion of the broader and holistic scope of health is the recognition that health inequities are shaped by structural and systematic differences in the social, economic, and environmental determinants of health. These are the conditions in which people are born, grow, live, learn, work, play, love, and age, which affect a wide range of health, functioning, and quality-of-life outcomes, including education, income, employment, housing, the physical environment, public safety, the social environment, transportation, etc. [5-7]. The interconnectedness of health with all policies acting on its determinants [8], originally stated in the Alma Ata Declaration on Primary Health Care [9] and the Ottawa Charter for Health Promotion [10], introduced a new spectrum for looking at health and implied a need for an integrated approach to population health [11,12].

For the purpose of this article, population health is understood as described and popularized by Kindig and Stoddart [13], which considers the "health outcomes and their distribution within a population, the patterns of determinants that influence such outcomes, and the policies that influence the optimal balance of determinants" [13]. The underlying assumption focuses on improving the health of the population rather than individuals and on promoting health equity through actions that target their main drivers, which are the social, economic and environmental conditions. Regarding health equity, it is referred here as "the principle underlying a commitment to reduce and, ultimately, eliminate disparities in health and in its determinants" [14].

\subsection{The EU Cohesion Policy and Health}

The concern for greater cohesion and solidarity—the key common principles of the EU—remains an essential feature underlying the process of integration and the creation of a "Europe of Regions" [15]. Since 1988, the EU invests in a regional policy to provide strategic assistance for European regions to achieve their full economic potential and development [16]. Measures taken toward this stated objective are implemented through EU regional and urban development policy, known as Cohesion Policy (CP) [17]. CP is the EU's strategy to stimulate, strengthen and support consistent development of its Member States (MS) and regions by reducing the existing economic, social, and territorial inequalities amongst them [18] through the allocation of funds in disadvantaged areas and sectors (Article 174 of the Treaty on the Functioning of the EU). This unique financial instrument, one which follows a multi-level governance model involving national, regional, and local authorities [19], is operationalized through the operational programs (OP), a multi-fund program, bringing together investments from the European Regional Development Fund (ERDF), the European Social Fund (ESF), and the Cohesion Fund [20]. The first contributes to economic and social cohesion in the EU by reducing imbalances amongst its regions and by enhancing competitiveness and territorial cooperation. The second invests in people by promoting employment, social inclusion, and education opportunities. The third provides support exclusively for the poorer regions of Europe.

The CP budget accounts for approximately one-third of the entire EU budget ( $€ 351.8$ billion in the period 2014-2020) [21], constituting significant opportunities for health-related investments [16], particularly toward the reduction of inequalities in key determinants of health [22]. There is extensive evidence that low socioeconomic status and low income are associated with poor health outcomes, particularly with respect to high mortality [2,23-26]. By allocating funds to the regions where development is lagging behind, CP could act as a major driver of health equity [27-29]. Most of the funds are targeted to those very regions with a gross domestic product (GDP) per capita under $75 \%$ of the EU average. This is the basis for the categorization of a region and its eligibility to receive funds. Recently, there was some debate around the use of the GDP as a single indicator to measure regional development. Beyond the different levels of GDP, there is an unequal distribution and allocation of other resources, power, and access to services, thus creating inequalities between regions and countries, which in turn generates inequities in health. $\mathrm{CP}$ contributes to reducing the gap between the better and worse performing regions by delivering funds that support job creation, business competitiveness, economic growth, sustainable development, and improve citizens' overall quality of 
life. These domains of intervention address conditions and factors influencing health positively or negatively - the so-called social, economic, environmental, and lifestyle-related determinants of health, i.e., factors that can be influenced by political, commercial and individual decisions-as opposed to age, sex, and genetic factors, which also influence health but are not, on the whole, open to influence by political or other types of policy [30,31].

Furthermore, $\mathrm{CP}$ funds help to deliver many EU objectives, as it complements policies from different sectors, such as those dealing with education, employment, energy, and the environment. Article 168 of the Treaty on the Functioning of the EU provides a scope for the "mainstreaming" of health into other policy areas, which required all European Commission (EC) activities to take health into consideration [32]. This is in line with the Health in All Policies (HiAP) framework, which was first introduced in Europe during the 2006 Finnish presidency of the EU. This framework aims to boost collaboration on the basis of greater inclusion of health considerations in policymaking across those policy sectors that influence health, such as environment, transportation, agriculture, land use, housing, and education, among others [33]. HiAP is currently a central element in the recent EU Health Strategy and also a part of the CP. However, the actual effectiveness of its official integration and impact assessment seems to be low, at both the EU and the country levels [32].

\subsection{The EURO-HEALTHY Population Health Index}

The Horizon 2020 EU-funded project EURO-HEALTHY (shaping EUROpean policies to promote HEALTH equitY), among other projects, looked to $\mathrm{CP}$ funds as resources with significant potential to decrease the health gap between the EU regions $[4,34]$. The project aimed to advance knowledge regarding population health across Europe, with particular attention at NUTS (Nomenclature of Territorial Units for Statistics) level 2 regions, the geographical and administrative level corresponding to the category of eligibility for receiving $\mathrm{CP}$ funds.

Due to the comprehensive nature of health inequalities, including, among others, the various social, cultural, behavioral, environmental, and political differences amongst the respective healthcare systems across Europe $[4,35]$, there is a need for enhanced evidence on the main drivers of regional health inequality to better guide policies and the allocation of $\mathrm{CP}$ funds.

Aligned with this, EURO-HEALTHY constructed a population health index (PHI)-a multidimensional measure - to evaluate population health inequalities across 10 areas of concern, with 17 dimensions and 39 indicators of health determinants and health outcomes across 269 NUTS 2 regions [4].

The construction of this index relied on the following key assumptions: (i) it is informed not only by the current state of the art and evidence on the different dimensions that population health entails, but also by the way health experts and stakeholders interpret that evidence and make use of their knowledge to evaluate population health [36]; (ii) it uses a sound methodology (MACBETH-measuring attractiveness by a categorical-based evaluation technique) and makes use of principles and concepts of multicriteria value measurement that avoid the common critical mistakes that often occur in the construction of indices [36,37]; (iii) it enables aggregate and disaggregated analyses of multilevel indices (e.g., for health determinants vs. outcomes, for areas of concern and for dimensions) [37].

Founded on these assumptions, the index presents a bottom-up hierarchical structure, providing an evidence-based analysis of regional health gaps in two indices-health determinants and health outcomes-divided into sub-indices corresponding to areas of concern that reflect broad domains to analyze population health: (i) economic conditions, social protection, and security, (ii) education, (iii) demographic change, (iv) lifestyle and health behaviors, (v) physical environment, (vi) built environment, (vii) road safety, (viii) healthcare resources and expenditure, (ix) healthcare performance, and $(\mathrm{x})$ health outcomes. Each area of concern is further divided into dimensions, which are independent evaluation axes for appraising population health, and are made operational by one or more indicators [4]. Indicators were selected through a wide Web-Delphi process where an international panel of 80 stakeholders and experts from multidisciplinary fields shared their views on which factors 
were deemed relevant to evaluate European population health [38]. The indicator data were collected for the year 2014 and retrieved from different official bodies, such as EUROSTAT, the European Environment Agency (EEA), and the World Health Organization (WHO) [39].

The results of its application to all NUTS 2 regions are publicly accessible from the WebGIS healthyregionseurope (https://healthyregionseurope.uc.pt) and are published in the "Atlas of Population Health in European Union Regions" [4].

This paper aims to analyze the regional planned investments for allocating $\mathrm{CP}$ funds in the period 2014-2020 and discuss their potential to reduce regional health inequalities, in light of the evidence provided by the EURO-HEALTHY PHI. Our underlying research questions are as follows:

(1) Do the intervention fields with planned allocation of CP funds match the dimensions where regions are lagging behind, as identified in the population health index?

(2) Are there any categories/intervention fields that are relevant for closing regional health gaps but appear to be currently underrepresented in $\mathrm{CP}$ planned investments?

\section{Materials and Methods}

\subsection{Materials}

This study is based on two main data sources: (i) the EURO-HEALTHY population health index and (ii) operational programs (OP) for Cohesion Policy Funding 2014-2020, involving the areas of intervention with planned allocation of funds in each region. All EU countries and regions were included in the analysis (269 NUTS 2), except for the seven outermost regions and autonomous cities due to data availability.

All the analyses conducted in this study take into account the three categories of regional eligibility for receiving CP funds, based on the regional GDP per capita: (1) less developed regions (LD) (GDP $<75 \%$ of the EU-27 average), (2) transition regions (TR) (GDP between $75 \%$ and $90 \%$ of the EU-27 average), and (3) more developed regions (MD) (GDP $>90 \%$ of the EU-27 average) (Figure 1).

\subsubsection{Population Health Index}

For this study, we used the value scores presented by all EU regions on the following dimensions of the health determinants: (i) employment; (ii) income and living conditions; (iii) security; (iv) education; (v) aging; (vi) lifestyle and health behaviors; (vii) pollution; (viii) housing conditions; (ix) water and sanitation; (x) waste management; (xi) road safety; (xii) healthcare resources; (xiii) healthcare performance (Figure 2). These dimensions correspond to policy intervention areas with impact on population health (positive or negative) and are associated to one or more determinants of health (Table 1). The value scores range between 0 (worse health) and 100 (better health) and were obtained through the application of a socio-technical methodological approach for the construction of indices, combining the multicriteria method MACBETH with Web-Delphi and decision conferencing processes $[4,34,36,37]$. These processes, using intuitive protocols of questioning, informed the shape of value functions (added value of improvements in indicators) and the weighting coefficients (importance of closing gaps in indicators). More information on the methodology and on the hierarchical multicriteria model can be found in Bana e Costa et al. [36,37]. 


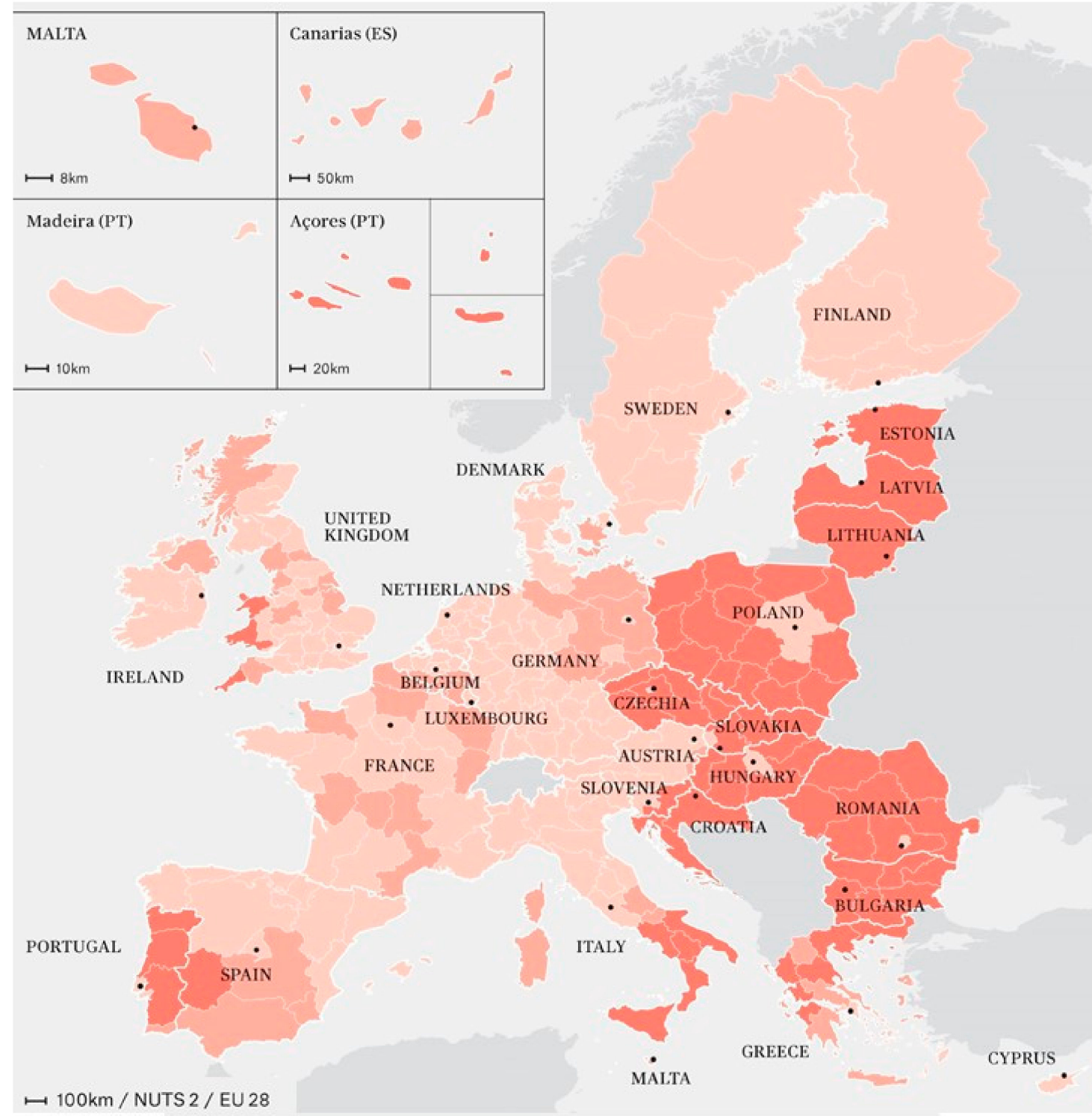

Regional elegibility for structural funds (2014-2020)

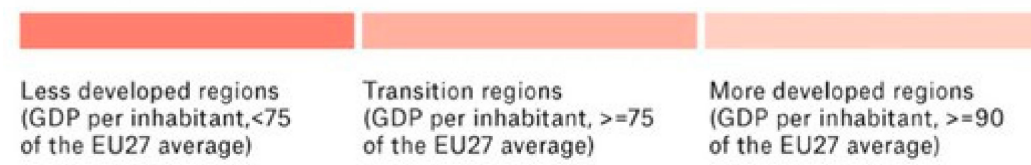

Figure 1. Regional eligibility map, 2014-2020. 

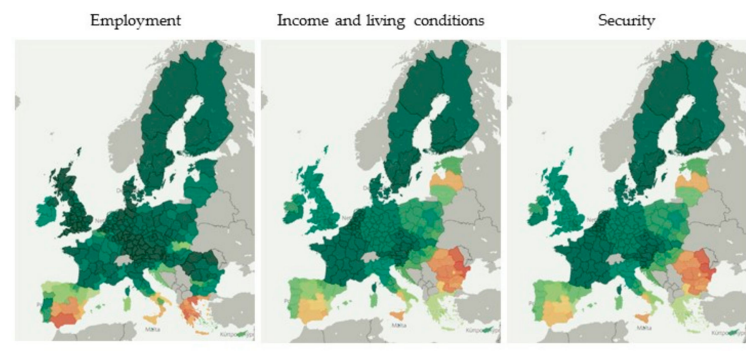

Education

Ageing

Lifestyle and health
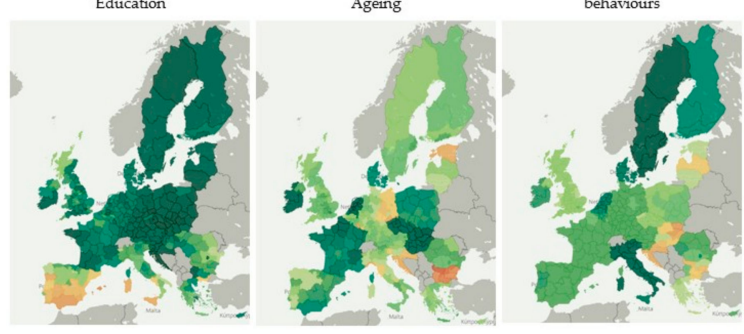

Pollotion
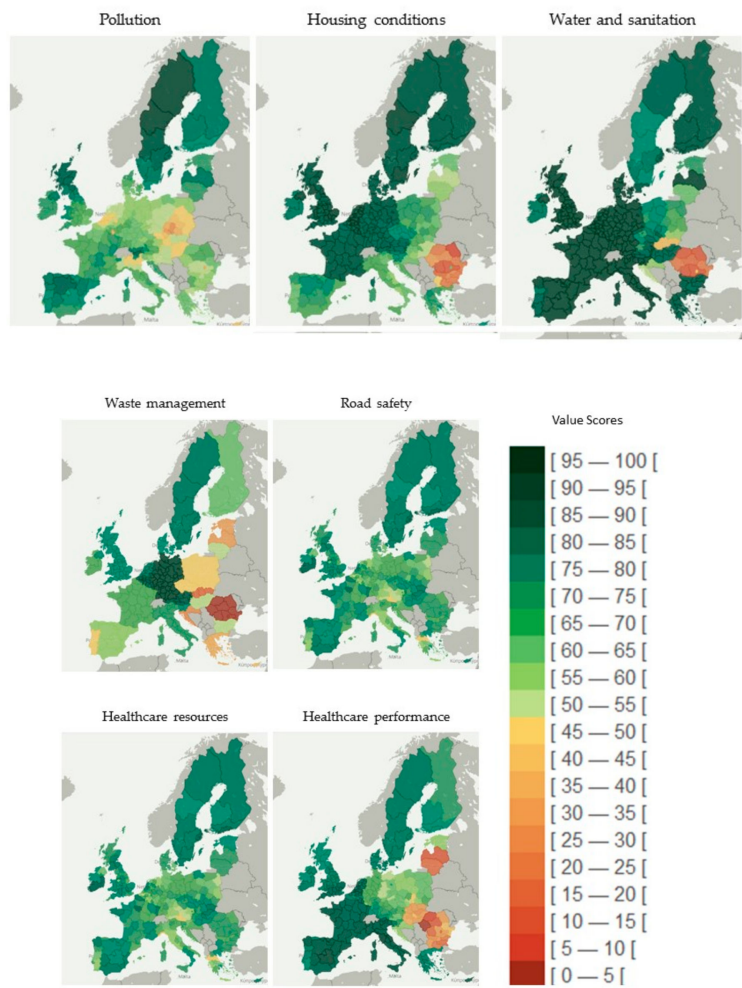

Figure 2. Geographical distribution of the population health index at regional level and across dimensions of health determinants. Note: The regional value-scores are classified in an equal interval scheme. This method divides the values into equal size range considering the minimum and maximum scores (from 0 to 100). The color coding of classes uses a gradation inspired by a traffic light system; red represents worse population health and green represents better health. 
Table 1. Population health index (PHI) structure.

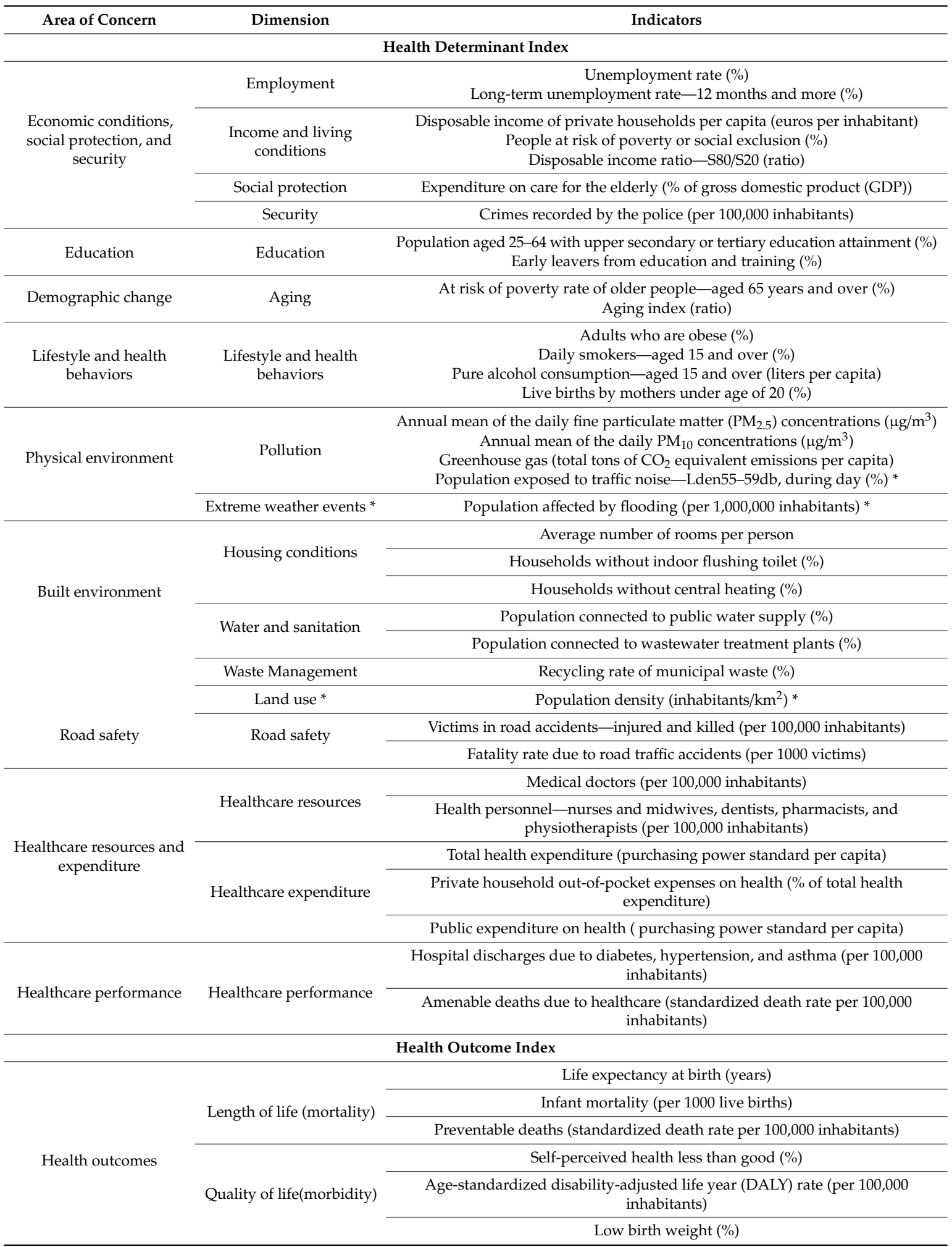

* Dimensions and indicators included in the PHI model (conceptual model) but not used in its application (adjusted model) to the 269 NUTS (Nomenclature of Territorial Units for Statistics) 2 regions, due to lack of data.

\subsubsection{Cohesion Policy Funding for 2014-2020}

Data regarding the CP funds for the period 2014-2020 were obtained from the EC data portal [40]. The data were extracted during 2017 for each one of the 385 operational programs (OP) of the current 
funding period (183 for ERDF, 155 for ESF, 22 for CF, and 25 ERDF-ESF) and included the following: (1) identifier; (2) title; (3) country code; (4) targeted region/city; (5) type of funding (ERDF, ESF, CF, or multi); (6) amount; (7) priority axes; (8) intervention codes.

From the 123 intervention field codes, organized in nine broader areas of interventions that represent the categories of actions or activities covered by the CP funds for the period 2014-2020, 59 codes were selected and used in the analyses (Table 2). In order to be included in the analysis, an intervention field code had to be linked to one or more population health dimensions of the PHI, meaning that the actions or activities described by the intervention field were directly or indirectly addressing one or more health determinants appraised within the PHI dimension.

Table 2. Cohesion Policy funding categories and intervention fields for the period 2014-2020.

\begin{tabular}{|c|c|c|}
\hline $\begin{array}{l}\text { Categories and } \\
\text { Intervention Field } \\
\text { Dimension }\end{array}$ & Code & Intervention Field \\
\hline \multirow{8}{*}{ A-Energy infrastructure } & 009 & Renewable energy: wind \\
\hline & 010 & Renewable energy: solar \\
\hline & 011 & Renewable energy: biomass \\
\hline & 012 & $\begin{array}{c}\text { Other renewable energy (including hydroelectric, geothermal, and marine energy) and } \\
\text { renewable energy integration (including storage, power to gas, and renewable hydrogen } \\
\text { infrastructure) }\end{array}$ \\
\hline & 013 & $\begin{array}{c}\text { Energy efficiency renovation of public infrastructure, demonstration projects and supporting } \\
\text { measures }\end{array}$ \\
\hline & 014 & $\begin{array}{c}\text { Energy efficiency renovation of existing housing stock, demonstration projects, and supporting } \\
\text { measures }\end{array}$ \\
\hline & 015 & $\begin{array}{l}\text { Intelligent Energy Distribution Systems at medium and low voltage levels (including smart } \\
\text { grids and information and communication technology (ICT) systems) }\end{array}$ \\
\hline & 016 & High-efficiency co-generation and district heating \\
\hline \multirow{7}{*}{$\begin{array}{l}\text { A-Environmental } \\
\text { infrastructure }\end{array}$} & 017 & Household waste management (including minimization, sorting, recycling measures) \\
\hline & 018 & $\begin{array}{l}\text { Household waste management (including mechanical biological treatment, thermal treatment, } \\
\text { incineration, and landfill measures) }\end{array}$ \\
\hline & 019 & Commercial, industrial, or hazardous waste management \\
\hline & 020 & $\begin{array}{c}\text { Provision of water for human consumption (extraction, treatment, storage, and distribution } \\
\text { infrastructure) }\end{array}$ \\
\hline & 021 & $\begin{array}{l}\text { Water management and drinking water conservation (including river basin management, water } \\
\text { supply, specific climate change adaptation measures, district and consumer metering, charging } \\
\text { systems, and leak reduction) }\end{array}$ \\
\hline & 022 & Wastewater treatment \\
\hline & 023 & $\begin{array}{l}\text { Environmental measures aimed at reducing and/or avoiding greenhouse gas emissions } \\
\text { (including treatment and storage of methane gas and composting) }\end{array}$ \\
\hline \multirow{7}{*}{$\begin{array}{l}\text { A-Transport } \\
\text { infrastructure }\end{array}$} & 028 & Trans-European Transport Network (TEN-T) motorways and roads-core network (new build) \\
\hline & 029 & $\begin{array}{c}\text { Trans-European Transport Network (TEN-T) motorways and roads-comprehensive network } \\
\text { (new build) }\end{array}$ \\
\hline & 030 & Secondary road links to TEN-T road network and nodes (new build) \\
\hline & 031 & Other national and regional roads (new build) \\
\hline & 032 & Local access roads (new build) \\
\hline & 033 & Trans-European Transport Network (TEN-T) reconstructed or improved road \\
\hline & 034 & Other reconstructed or improved road (motorway, national, regional, or local) \\
\hline \multirow[b]{2}{*}{ A-Sustainable transport } & 043 & Clean urban transport infrastructure and promotion (including equipment and rolling stock) \\
\hline & 044 & $\begin{array}{l}\text { Intelligent transport systems (including the introduction of demand management, tolling } \\
\text { systems, IT monitoring, control and information systems) }\end{array}$ \\
\hline \multirow{7}{*}{ B-Public facilities } & 049 & Education infrastructure for tertiary education \\
\hline & 050 & Education infrastructure for vocational education and training and adult learning \\
\hline & 051 & Education infrastructure for school education (primary and general secondary education) \\
\hline & 052 & Infrastructure for early childhood education and care \\
\hline & 053 & Health infrastructure \\
\hline & 054 & Housing infrastructure \\
\hline & 055 & Other social infrastructure contributing to regional and local development \\
\hline \multirow{4}{*}{$\begin{array}{l}\text { C-Business } \\
\text { development }\end{array}$} & 068 & 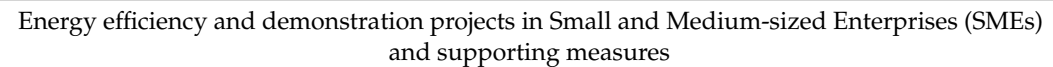 \\
\hline & 069 & Support to environmentally friendly production processes and resource efficiency in SMEs \\
\hline & 070 & Promotion of energy efficiency in large enterprises \\
\hline & 071 & $\begin{array}{l}\text { Development and promotion of enterprises specialized in providing services contributing to the } \\
\text { low-carbon economy and to resilience to climate change (including support to such services) }\end{array}$ \\
\hline
\end{tabular}


Table 2. Cont.

\begin{tabular}{|c|c|c|}
\hline $\begin{array}{l}\text { Categories and } \\
\text { Intervention Field } \\
\text { Dimension }\end{array}$ & Code & Intervention Field \\
\hline \multirow[b]{2}{*}{$\mathrm{C}-\mathrm{ICT}$} & 080 & \multirow{2}{*}{$\begin{array}{c}\text { E-inclusion, e-accessibility, e-learning, and e-education services and applications, digital literacy } \\
\text { ICT solutions addressing the healthy active aging challenge, and e-health services and } \\
\text { applications (including e-care and ambient assisted living) }\end{array}$} \\
\hline & 081 & \\
\hline \multirow{5}{*}{ C-Environment } & 083 & Air quality measures \\
\hline & 084 & Integrated pollution prevention and control (IPPC) \\
\hline & 085 & Protection and enhancement of biodiversity, nature protection, and green infrastructure \\
\hline & 089 & Rehabilitation of industrial sites and contaminated land \\
\hline & 090 & Cycle tracks and footpaths \\
\hline \multirow{7}{*}{ D—Employment } & 102 & $\begin{array}{l}\text { Access to employment for jobseekers and inactive people, including the long-term unemployed } \\
\text { and people far from the labor market, also through local employment initiatives and support for } \\
\text { labor mobility }\end{array}$ \\
\hline & 103 & $\begin{array}{l}\text { Sustainable integration into the labor market of young people, those not in employment, } \\
\text { education or training, including young people at risk of social exclusion and young people from } \\
\text { marginalized communities, including through the implementation of the youth guarantee }\end{array}$ \\
\hline & 104 & $\begin{array}{l}\text { Self-employment, entrepreneurship and business creation including innovative micro, small- } \\
\text { and medium-sized enterprises }\end{array}$ \\
\hline & 105 & $\begin{array}{l}\text { Equality between men and women in all areas, including in access to employment, career } \\
\text { progression, reconciliation of work and private life, and promotion of equal pay for equal work }\end{array}$ \\
\hline & 106 & Adaptation of workers, enterprises, and entrepreneurs to change \\
\hline & 107 & Active and healthy aging \\
\hline & 108 & $\begin{array}{l}\text { Modernization of labor market institutions, such as public and private employment services, } \\
\text { and improving the matching of labor market needs, including through actions that enhance } \\
\text { transnational labor mobility, as well as through mobility schemes and better cooperation } \\
\text { between institutions and relevant stakeholders }\end{array}$ \\
\hline \multirow{6}{*}{ E-Inclusion } & 109 & \multirow{6}{*}{$\begin{array}{c}\text { Active inclusion, including with a view to promoting equal opportunities and active } \\
\text { participation, and improving employability } \\
\text { Socio-economic integration of marginalized communities such as Roma } \\
\text { Combating all forms of discrimination and promoting equal opportunities } \\
\text { Enhancing access to affordable, sustainable, and high-quality services, including healthcare and } \\
\text { social services of general interest } \\
\text { Promoting social entrepreneurship and vocational integration in social enterprises and the } \\
\text { social and solidarity economy in order to facilitate access to employment } \\
\text { Community-led local development strategies }\end{array}$} \\
\hline & 110 & \\
\hline & 111 & \\
\hline & 112 & \\
\hline & 113 & \\
\hline & 114 & \\
\hline \multirow{3}{*}{ F-Lifelong learning } & 115 & \multirow{3}{*}{$\begin{array}{l}\text { Reducing and preventing early school-leaving and promoting equal access to good-quality } \\
\text { early-childhood, primary, and secondary education including formal, non-formal, and informal } \\
\text { learning pathways for reintegrating into education and training } \\
\text { Improving the quality and efficiency of, and access to, tertiary and equivalent education with a } \\
\text { view to increasing participation and attainment levels, especially for disadvantaged groups } \\
\text { Enhancing equal access to lifelong learning for all age groups in formal, non-formal, and } \\
\text { informal settings, upgrading the knowledge, skills, and competences of the workforce, and } \\
\text { promoting flexible learning pathways including through career guidance and validation of } \\
\text { acquired competences } \\
\text { Improving the labor market relevance of education and training systems, facilitating the } \\
\text { transition from education to work, and strengthening vocational education and training systems } \\
\text { and their quality, including through mechanisms for skills anticipation, adaptation of curricula, } \\
\text { and the establishment and development of work-based learning systems, including dual } \\
\text { learning systems and apprenticeship schemes }\end{array}$} \\
\hline & 117 & \\
\hline & 118 & \\
\hline
\end{tabular}

Source: Commission Implementing Regulation (EU) No 215/2014, of 7 March 2014, Annex I-Nomenclature for the categories of intervention of the Funds under the Investment for growth and jobs goal and of the Youth Employment Initiative. Main categories of intervention (European Regional Development Fund (ERDF), the European Social Fund (ESF), and the Cohesion Fund (CF)): A-infrastructure providing basic services and related investment; B - social, health, and education infrastructure investment; C-development of endogenous potential; D-promoting sustainable and quality employment and labor mobility; E-promoting social inclusion, combating poverty, and any discrimination; F-investing in education, training, and vocational training for skills and lifelong learning.

\subsection{Methods}

Methods applied in this study aimed to explore the link between the current $\mathrm{CP}$ funding scheme and the dimensions of health determinants appraised in the EURO-HEALTHY PHI, looking to the regional performance in each of those dimensions.

In the first stage, several inferential statistics were applied to verify the presence of health inequalities across regions within each PHI dimension considering the regional level of development, i.e., the three categories for regional eligibility (LD, TR, and MD). In the first step, the Levene test for equality of variances was applied to verify the assumption of homogeneity of variance. Since the 
number of regions is different between categories and the PHI dimensions revealed unequal variance, the Welsh's test was performed. Welch's one-way analysis of variance (ANOVA) allowed for examining whether the different regional scores in each dimensional sub-index were statistically different across the three categories of regions. Then, the post hoc Games-Howell test was executed to identify which category mean was statistically different from the other two.

Finally, a two-dimensional matrix was built to represent the link between the $\mathrm{CP}$ categories for intervention and the PHI dimensions. Departing from this matrix and using the data on CP funds allocation by region and intervention field dimensions, descriptive statistics were used to identify those fields where the majority of funds (intervention fields with a higher number of NUTS 2) are concentrated and, in turn, verify the conformity with the priority intervention areas given by the PHI (dimensions with the lowest health scores by category of region).

\section{Results}

\subsection{Population Health Index and Regional Level of Development}

The ANOVA analysis revealed significant differences in the mean values of regional scores in most PHI dimensions (Table 3). In only three dimensions-education, aging, and road safety-regional scores did not vary significantly ( $p$-value is not statistically significant).

Table 3. ANOVA statistics by dimensional sub-index.

\begin{tabular}{ccc}
\hline Population Health Index Dimensions-Health Determinants & Welch's $t$-Test & $p$-Value \\
\hline Employment & 15.112 & $0.000^{*}$ \\
Income and living conditions & 32.879 & $0.000^{*}$ \\
Security & 22.979 & $0.000^{*}$ \\
Education & 7.488 & 0.001 \\
Aging & 0.899 & 0.410 \\
Lifestyles and health behaviors & 28.000 & $0.000^{*}$ \\
Pollution & 11.899 & $0.000^{*}$ \\
Housing conditions & 57.107 & $0.000^{*}$ \\
Water and sanitation & 27.124 & $0.000^{*}$ \\
Waste management & 79.516 & $0.000^{*}$ \\
Road safety & 0,186 & 0.831 \\
Healthcare resources & 82.760 & $0.000^{*}$ \\
Healthcare performance & 38.083 & $0.000 *$ \\
\hline
\end{tabular}

Note: ${ }^{*} p$-value $<0.001$.

Figure 3 presents the mean differences between LD and MD regions, by dimensional sub-index. In nearly all of the underlying health determinants included in the PHI, LD regions present worse scores when compared with MD regions. Scores presented by LD regions are particularly low in the dimensions of healthcare performance, housing conditions, and waste management, where the mean difference between the LD and MD regions was particularly higher $(-27.8,-26.8$, and -34.6 , respectively).

\subsection{Cohesion Policy Funds Allocation by Intervention Field and Category of Region}

Figure 4 shows employment (98.9\%), social inclusion (98.9\%), and lifelong learning $(94.8 \%)$ as the intervention field dimensions presenting the highest number of regions with planned investment. There is also a high proportion of regions allocating resources to energy infrastructure and to development of endogenous potential, specifically related to energy (90\%) and business development (86.2\%). LD regions are more prominently represented in the majority of the intervention fields, compared with TR and MD regions, particularly among the following fields: social, health and education infrastructure and related investment, environmental infrastructure, and endogenous potential: information and 
communications technology (ICT). For these three fields, substantially more programs and investments are planned amongst LD regions (73\% on average) compared with TR and MD (16\% and 35.6\%, respectively on average). Supplementary Material 1 offers a series of maps depicting the geographical distribution of funds allocation by intervention field dimension across EU regions, highlighting LD regions.

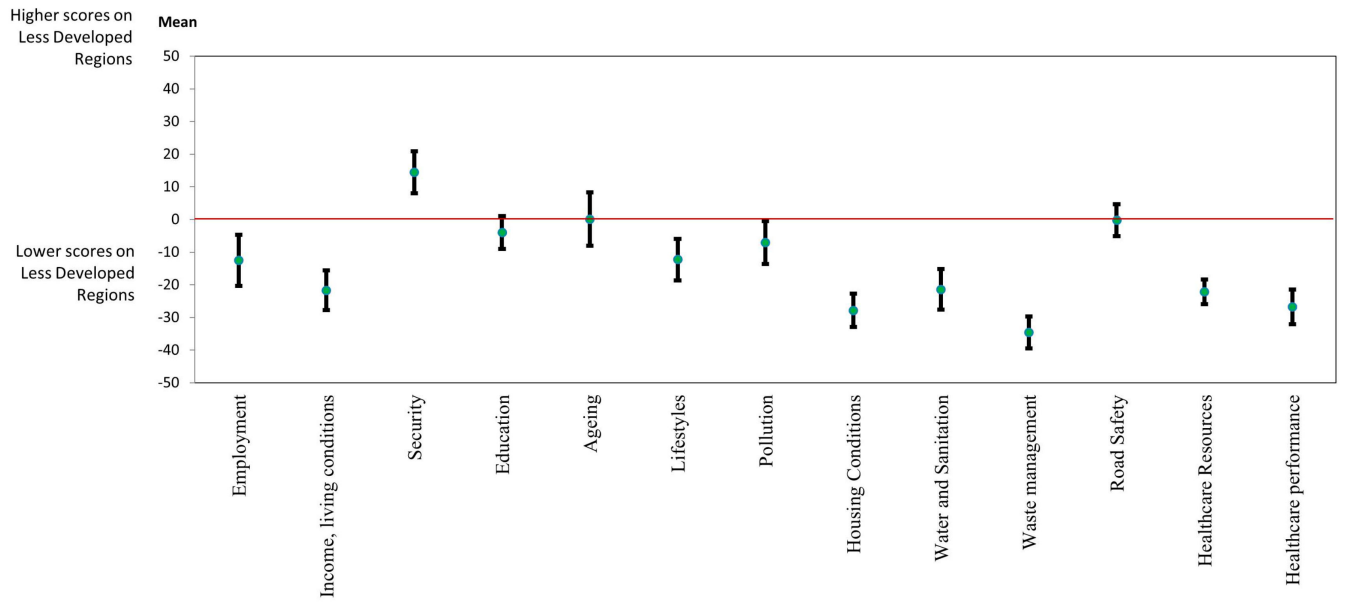

Figure 3. Mean differences between less developed (LD) regions and more developed (MD) regions, by dimensional sub-index. Note: The interval plots display $95 \%$ confidence intervals (CI) for each mean difference. Each dot represents the value of the mean difference in each dimensional sub-index: negative values in a dimension (below 0 ) indicate that LD regions perform worse than MD regions in that dimension; positive values in a dimension (above 0 ) indicate that LD regions perform better than MD regions in that dimension. If an interval does not contain 0 , the corresponding means are significantly different.

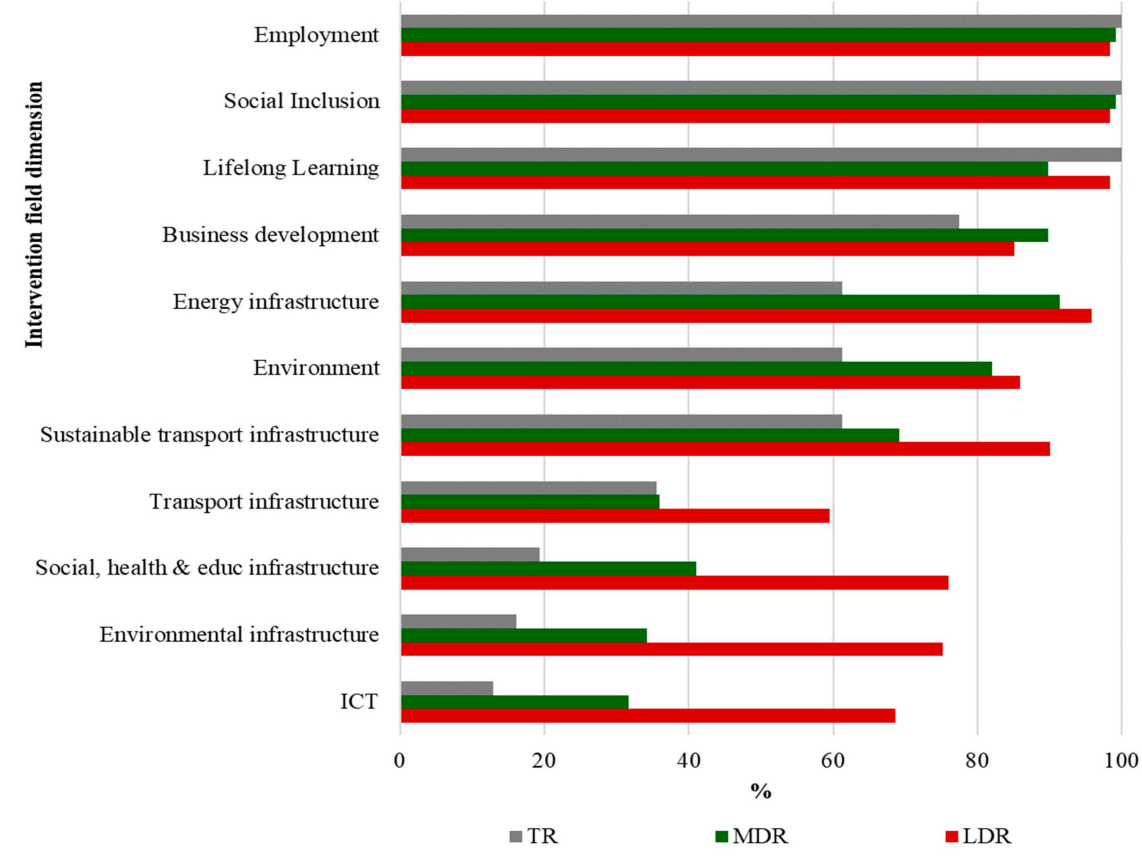

Figure 4. Percentage of NUTS 2 regions with allocated investment in each intervention field dimension, by category of region. Note: Numbers are calculated as a percentage of the number of regions within each category of region (LD, transition region (TR), and MD). 
The intervention field dimensions addressed most are (1) access to employment for job-seekers and inactive people, (2) energy efficiency renovation of public infrastructure, (3) active inclusion, (4) reducing and preventing early school leaving, and (5) adaptation of workers, enterprises and entrepreneurs. These interventions were the main priority investments for more than $90 \%$ of $\mathrm{LD}$ regions (see Supplementary Material 2). When looking at intervention fields addressing health directly, we can distinguish four types of actions: (1) enhancing access to affordable, sustainable, and high-quality health and social services (63.6\%); (2) ICT solutions to assist with healthy active aging $(60.3 \%$ of regions); (3) health infrastructure (54.5\% of regions); (4) active and healthy aging (35.5\%).

\subsection{Cohesion Policy Categories of Intervention and the Population Health Index Dimensions}

Table 4 presents the PHI dimensions, integrating the health determinants component, which are potentially addressed by the CP intervention fields defined for the period 2014-2020. Overall, 11 categories represent the intervention fields where actions address health determinants as measured by the PHI (see Table 1 to view the indicators within each dimension and Table 2 where information on the type of interventions within each intervention field dimension is provided).

The intervention field dimension inclusion (promoting social inclusion, combating poverty and discrimination) addresses almost all the PHI dimensions, with exceptions for pollution, water and sanitation, road safety, and healthcare performance. In contrast, there are three intervention fields that have impact only in one PHI dimension, such as (1) energy infrastructure and sustainable transport addressing pollution, and (2) lifelong learning addressing education. From the analysis of intervention fields, no interventions with impact on the dimension of healthcare performance were identified; this may well indicate the missing CP investment in that dimension. On the other hand, the PHI dimensions pollution, education, employment, and income and living conditions can be found in at least four $\mathrm{CP}$ intervention field dimensions. This means that these health determinants can be targeted through a set of $\mathrm{CP}$ fields.

Table 5 provides the number of regions within each category of region (LD, TR, and MD) that performed worse (scores below 50) in each dimension of the PHI, as well as how many from these regions indicated $\mathrm{CP}$ fund allocation in intervention fields addressing those dimensions.

Overall, half of the EU regions (135 out of 269) present low scores in one or more dimensions of health determinants; $97.5 \%$ are $\mathrm{LD}$ regions.

The dimensions of waste management and healthcare resources present the higher number of regions performing worse (respectively, 63 and 52 out of 269 regions); in more than one-third of LD regions (46 and 38 out of 121 LD regions), these dimensions are critical, presenting health scores below 50 (PHI ranges between 0 and 100). Conversely, road safety is the PHI dimension where only five regions show low health scores.

A correspondence exists between the dimensions identified as critical in each region and the respective $\mathrm{CP}$ allocated investment in intervention fields capable of improving indicators within those dimensions; this is the case for all dimensions, with the exception of aging, road safety, and healthcare performance, where there are regions that did not plan to allocate funds to any intervention field with potential impact on these dimensions. In the case of healthcare performance, no correspondence with the $\mathrm{CP}$ intervention fields was found. 
Table 4. Matrix of Cohesion Policy intervention field dimensions and the EURO-HEALTHY population health index dimensions.

\begin{tabular}{|c|c|c|c|c|c|c|c|c|c|c|c|c|c|}
\hline \multirow[b]{2}{*}{$\begin{array}{l}\text { Intervention Field } \\
\text { Dimensions }\end{array}$} & \multicolumn{13}{|c|}{ Population Health Index Dimensions-Health Determinants } \\
\hline & Employment & $\begin{array}{l}\text { Income, } \\
\text { Living } \\
\text { Conditions }\end{array}$ & Security & Education & Aging & Lifestyles & Pollution & $\begin{array}{l}\text { Housing } \\
\text { Conditions }\end{array}$ & $\begin{array}{l}\text { Water and } \\
\text { Sanitation }\end{array}$ & $\begin{array}{c}\text { Waste } \\
\text { Management }\end{array}$ & $\begin{array}{l}\text { Road } \\
\text { Safety }\end{array}$ & $\begin{array}{l}\text { Healthcare } \\
\text { Resources }\end{array}$ & $\begin{array}{l}\text { Healthcare } \\
\text { Performance }\end{array}$ \\
\hline Energy infrastructure & & & & & & & - & & & & & & \\
\hline $\begin{array}{l}\text { Environmental } \\
\text { infrastructure }\end{array}$ & & & & & & & - & & $\bullet$ & - & & & \\
\hline Transport infrastructure & & & & & & & & & & & • & & \\
\hline Sustainable transport & & & & & & & - & & & & & & \\
\hline Public facilities & & - & & • & & & & - & & & & • & \\
\hline Business development & - & & & & & & - & & & & & & \\
\hline ICT & $\bullet$ & $\bullet$ & & $\bullet$ & $\bullet$ & & & & & & & $\bullet$ & \\
\hline Environment & & & & & & - & - & & & & & & \\
\hline Employment & $\bullet$ & $\bullet$ & & & $\bullet$ & & & & & & & & \\
\hline Inclusion & - & - & - & - & - & - & & - & & - & & - & \\
\hline
\end{tabular}

Note: The dots indicate a relationship between the intervention field dimension and the PHI dimensional health sub-index (e.g., interventions made in energy infrastructure have a potential impact on the indicators that integrate the dimension of pollution). 
Table 5. Number of European Union (EU) regions with the lowest scores and with CP allocated investment, by category of region and dimensional health sub-index.

\begin{tabular}{ccccccccc}
\hline $\begin{array}{c}\text { PHI Dimensional } \\
\text { Health Sub-Indices }\end{array}$ & \multicolumn{3}{c}{$\begin{array}{c}\text { Number of Regions with Scores } \\
\text { Below 50 }\end{array}$} & \multicolumn{3}{c}{$\begin{array}{c}\text { Number of Regions with the Lowest Scores } \\
\text { and with Allocated Investment }\end{array}$} \\
\cline { 2 - 10 } & LD & TR & MD & Total & LD & TR & MD & Total \\
\hline Employment & 10 & 10 & 2 & 22 & 10 & 10 & 2 & 22 \\
Income and living conditions & 17 & 4 & 1 & 22 & 17 & 4 & 1 & 22 \\
Security & 5 & 12 & 14 & 31 & 5 & 12 & 14 & 31 \\
Education & 8 & 7 & 4 & 19 & 8 & 7 & 4 & 19 \\
Aging & 9 & 7 & 5 & 21 & 9 & 7 & 4 & 20 \\
Lifestyles and health behaviors & 14 & 0 & 0 & 14 & 14 & - & - & 14 \\
Pollution & 14 & 1 & 22 & 37 & 14 & 1 & 22 & 37 \\
Housing conditions & 13 & 0 & 0 & 13 & 13 & - & - & 13 \\
Water and sanitation & 10 & 0 & 2 & 12 & 10 & - & 2 & 12 \\
Waste management & 46 & 8 & 9 & 63 & 46 & 8 & 9 & 63 \\
Road safety & 2 & 0 & 3 & 5 & 2 & - & 0 & 2 \\
Healthcare resources & 38 & 8 & 6 & 52 & 38 & 8 & 6 & 52 \\
Healthcare performance & 24 & 0 & 3 & 27 & 0 & - & 0 & 0
\end{tabular}

Note: Calculations based on the matrix of CP intervention field dimensions (see Table 4) and the EURO-HEALTHY PHI dimensions (see Table 1). For each region, dimensions presenting value scores below 50 (PHI ranges between 0 and 100) and CP intervention field dimensions with planned investment were identified. For a region to be considered one with allocated investment addressing the PHI dimension, it should present at least one CP intervention field dimension with potential impact on the dimensional health sub-index with lowest scores.

\section{Discussion}

This paper aimed both to analyze the regional planned investments for allocating $\mathrm{CP}$ funds in the period 2014-2020 and to discuss their potential for reducing regional health inequalities in light of the evidence provided by the EURO-HEALTHY project and, specifically, by the population health index (PHI). The PHI collects data on key determinants of health in EU regions, providing insights into the factors which shape population health outcomes and fuel health inequalities. Its findings can have important implications for improving the process of setting priorities and of planning the allocation of $\mathrm{CP}$ funds which can be earmarked to positively impact health determinants.

Our first research question was to ascertain whether the intervention fields with planned allocation of $\mathrm{CP}$ funds were addressing the dimensions of health determinants where regions were lagging behind, that is, presenting worse scores in those dimensions.

Significant differences between the three categories of regions (LD, TR, and MD) were found in most PHI dimensions of health determinants. With the exception of pollution and security, LD regions present significantly worse population health scores in all dimensions of health determinants, compared with those presented by MD regions. There is a significant gap between the regions in the dimensions of housing conditions, waste management, and healthcare performance. Access to quality and affordable housing is a basic need for healthy living and is a key determinant measure to alleviate poverty and social exclusion [7]. CP funds can play an important role to ensure that every EU citizen, regardless the country or region of residence, has access to safe housing conditions. The group of regions that fall behind in terms of providing safe housing are often the new Member States (e.g., Bulgaria, Romania) [4]. CP investments addressing improved quality in housing, namely, the availability of sufficient living space within the dwelling, the existence of an indoor flushing toilet, and central heating, would contribute positively to obtaining better health scores in these regions. Central heating represents a core concern for population health in southern European regions [41] namely, Portugal, Spain, Italy, and Greece, where most of the population lives in homes without central heating (regional rates above 50\%) [4].

On the other hand, regions across the EU, regardless of their level of development, face low health scores in the dimension of aging; no significant differences between LD and MD regions were found, meaning that all countries are experiencing an increase in their older populations. Nonetheless, unbalanced demographic structures could have a worse impact on fragile and less prepared social and 
health systems [35,42]. According to the literature, CP fund allocation can ameliorate those impacts though investment in categories of intervention dealing with, for example, "ICT solutions for healthy and active aging" [43], "lifelong learning opportunities" [44], "employment at an older age" [45], and "access to affordable, sustainable, and high-quality health and social services" [46].

The CP budget creates favorable conditions to achieve integrated development in population health-related fields, with guidelines that deal with how $\mathrm{CP}$ investments are directly applied into health systems to improve their effectiveness, accessibility, and resilience. However, the emphasis of $\mathrm{CP}$ on economic growth overshadows the importance of improving population health and overall well-being.

In general, the regional planned investments for $\mathrm{CP}$ funds are linked to the dimensions analyzed in the EURO-HEALTHY PHI. Most regions planned to allocate their funds to those interventions which represent a variety of multidimensional and multi-sectorial aspects influencing the health and well-being of people, as reflected in the rationale of the PHI.

Firstly, the most frequent correspondence was found between the PHI dimensions reflecting economic and living conditions and interventions that stimulate employment, support the labor market, promote social inclusion, and combat poverty. A high concentration of $\mathrm{CP}$ planned investments across regions are addressing the aforementioned domains, which the PHI identified as key dimensions responsible for polarization or social inequity across EU regions. Nearly all regions (95.9\% and 86.6\%) indicate the intention to allocate funds aimed at promoting active inclusion (with a view to promoting equal opportunities, active participation, and employability) and at enhancing equal access to lifelong learning for all ages. In 2015, the number of EU citizens at risk for poverty or social exclusion was estimated, on average, at $24.5 \%$ of the population, with countries such as Bulgaria, Greece, Hungary, Latvia, Lithuania, Romania, Portugal, Cyprus, and Croatia registering rates above the EU average. The highest rates of poverty and social exclusion were reported in the following LD regions: Sicilia, Italy (55.8\%), Sud-Est, Romania (52.9\%), and Campania, Italy (49\%) [4].

Evidence from the PHI also confirms that large differences in education still exist across Europe: regions in north-central Europe present significantly higher health scores linked to good educational levels when compared with southern European regions (from Portugal, Spain, and Italy), where there is a concentration of worse performances. Dropping out of school is a multi-faceted and complex problem that increases the risk of unemployment, poverty, and social exclusion [47,48]. Another essential aspect addressed by CP funds pertains to education and combating school dropouts. The intervention fields of "reducing and preventing early school leaving" and "promoting equal access to good-quality early-childhood, primary, and secondary education" has planned investment in $90.1 \%$ of LD regions.

Secondly, aspects related with physical and built environment bring together a significant number of interventions addressing pollution, as they are related with energy efficiency, sustainable transport, and overall environmental infrastructures. Dimensions such as water and sanitation, waste management, and road safety are also addressed by a fair number of interventions. The research findings provide evidence that can help to confirm that $\mathrm{CP}$ can have a major impact on, for example, improving regional systems of waste collection and treatment [49-51]. A category of intervention with a significant amount of planned CP investment is "energy infrastructure". Of reference are LD regions that are dedicating CP funds to "energy efficiency renovation of public infrastructure" $(94.2 \%$ of regions), "energy efficiency renovation of existing housing stock" ( $88.4 \%$ of regions) and "clean urban transport infrastructure" (82.6\% of regions), and "air quality measures" (62.8\%). These interventions provide the opportunity to address the problems of high concentrations of air pollution (linked to intra-regional sources) among the LD regions (mostly east-central Europe), compared with their more affluent counterparts [4]. According to EURO-HEALTHY PHI, it is estimated that 157 million Europeans live in regions of significant concern in terms of the quality of one's physical environment, measured by fine particulate matter $\left(\mathrm{PM}_{2.5}\right), \mathrm{PM}_{10}$, and greenhouse gas indicators, and in terms of receiving the lowest population health value score (physical environment index $<50$ ). These regions are mainly concentrated in east-central Europe [4] and are included in the group of countries allocating 
$\mathrm{CP}$ funds to interventions with potential to change the current air quality performance. Of mention are the priorities of investment in "energy infrastructure" and "sustainable transport infrastructure" (see Supplementary Material 2).

The second research question that this study aimed to explore was the verification of whether there were any categories and intervention fields that were identified as relevant for closing the regional gaps (considering the evidence of the PHI) but which appeared to be currently underrepresented in the CP planned investments. Results show that, while major upstream determinants of health seemed to be frequently addressed (e.g., employment, income and living conditions, education), other dimensions directly linked with the health sector remain underrepresented in funds allocation schemes. This is the case for healthcare performance, a dimension where a considerable number of regions are lagging behind, mostly LD regions from the Baltic and Eastern European countries (Latvia, Lithuania, Romania, Bulgaria, Slovakia, and Hungary). Worse scores in these regions call for urgent interventions aiming at both reducing amenable mortality due to healthcare and preventing hospital stays due to diabetes, hypertension, and asthma [4].

The current Third Health Program (2014-2020) seeks to promote innovative, efficient, and sustainable health systems, with EC encouraging MS to invest in the cost-effectiveness and sustainability of health systems and access to health services for all social groups [52]. Although opportunities for health investments through European Structural and Investments Funds (ESIF) (including CP funds) were widely communicated by the Commission [16,53], this area remains rather unexploited. Fund allocation can be significantly improved, given that the health sector in Europe accounts for $10 \%$ of the EU's GDP and represents the core of the EU's social protection [52].

Given its ability to provide a comprehensive picture of big data through indices, the PHI presents the potential to navigate fund allocation in a direction of greater health equity across European regions. This would also allow for the necessary expanding of those eligibility criteria that are currently narrowed to GDP per capita, despite the common evidence that this is only one indicator amongst many. The Juncker Plan for improved and more strategic use of CP and ESIF (also in combination) is already incorporating some of these needs. Moreover, the EC's proposal for a future strategy for the 2020-2027 budget period suggests new criteria, in addition to GDP, for analyzing fund allocation. As an assessment tool, the PHI will allow for improved target specific fund allocation to local and regional specificities and needs of EU regions.

The PHI could act as an informing tool that could facilitate a more focused and targeted distribution of CP funds. This rationale is also in line with the 2018 report of the multi-stakeholder platform on the implementation of the United Nations sustainable development goals (SDGs) in the EU, which seeks to advise the EC on implementing the SDGs through the adjustment of the next multi-annual financial framework. By underscoring the importance of the 2030 Agenda for Sustainable Development, which has at its core the 17 SDGs with 169 targets, the report suggests the need to restructure the CP funds for the post-2020 period, specifically by adjusting the allocation criteria through new indicators to better reflect economic, social, and environmental aspects. The argument presented is that it is counterproductive to develop funding frameworks which incentivize expenditure that is harmful to the environment and health or likely to increase disparities in well-being. The determination as to which regions will receive $\mathrm{CP}$ funding should be supported by a much more refined basis of evidence that not only identifies those regions which lag behind, but also makes reference to specific dimensions and indicators. The PHI, through its model disaggregated into dimensions and indicators, can provide useful information for the potential establishment of a new scheme of funding which goes beyond the GDP as the only measure on which the definition of regional eligibility categories is based. 


\section{Limitations}

$\mathrm{CP}$ funds are allocated in ways that indirectly consider health determinants and health outcomes. Further research should be conducted to identify the types of evidence and instruments that are required to support the EU and MS efforts to ensure that funds are most effectively and efficiently allocated to regions with the highest need.

For example, it would be highly relevant to study the implementation effectiveness of the use of $\mathrm{CP}$ funds addressing the PHI dimensions of health determinants considering its potential benefit to reduce the regional gaps in health. Moreover, the analysis of the previous (2007-2013) and current programming periods (2014-2020), upon conclusion of the latter, will enable comparisons to be drawn that may support a better allocation of funding in the future programming period.

The analysis of the OPs focuses solely on the three fund categories: ERDF, ESF, and CF. There are additional funds available within the ESIF that have the potential to support the mitigation of health inequalities across European regions, mainly the Agricultural Fund for Rural Development (EAFRD), the European Maritime and Fisheries Fund (EMFF), and European Territorial Cooperation (ETC): Interreg V. Nevertheless, they were beyond the scope of the present study's analysis.

Although the ANOVA analysis demonstrated that, in the majority of PHI dimensions, the regional population health scores present significant statistical variations by category (LD, TR, and MD), some caution is needed when analyzing the results. The independence of the observations (in this study, the regions) is one of the main assumptions of ANOVA. We defend the independence of the data regarding the population health index because the value score of one region did not depend on the value score of another region. Yet, we could not establish independence regarding the regional eligibility categories since they are not randomly assigned (regions are categorized by the EC according to their respective level of development as measured by GDP) [20].

Moreover, data from the PHI used in this study cover year 2014, and specific data gaps were identified throughout the EU regions and PHI indicators. Constraints on data availability at the regional level were found in dimensions within built environment, lifestyle and health behaviors, and healthcare performance [39].

Lastly, it is acknowledged that there are a variety of considerations which come into play during the process of setting funding priorities. One is the wide variation in the design, management, and performance of health systems across the EU, which may impact the level of supply and demand of healthcare in each country. Another may be the different forms of governance and the administrative capacity of national and regional authorities, which represent different levels of bureaucracy and may in turn influence the allocation of funds amongst competing priorities and planned investments.

Given these considerations, the PHI can provide additional evidence to apply in these negotiations and decision-making processes, promoting an evidence-based approach which the EC, as well as the MS and regional governments themselves, can use to develop guidelines for funding.

\section{Conclusions}

This study adds evidence to the current need to rethink how appropriately a country's GDP may serve as the sole eligibility criterion for allocating regional funds. The level of development measured by GDP is not a direct indication that a region with high GDP has good levels of health and well-being because population health is multidimensional and includes many factors beyond the level of economic development and income. Results shown by the EURO-HEALTHY PHI not only demonstrate that key dimensions of population health equity are underrepresented in the current funding scheme but also that regions with high GDP (classified as MD regions) present worse scores in important determinants negatively affecting health and well-being, such as public safety (a dimension of security) and air quality (a dimension of pollution).

The dimensions of aging, road safety, and healthcare performance appear to be currently underrepresented in $\mathrm{CP}$ planned investment. In fact, in the case of healthcare performance, no correspondence with the $\mathrm{CP}$ intervention fields was found. This shows that there is room of 
improvement on how to use cohesion funds to improve the health systems' effectiveness, accessibility and resilience, and accordingly achieve an integrated development in population health-related fields.

A fresh approach is needed to extend the current eligibility criteria into more dimensions. Using GDP as the sole measurement of eligibility presents limitations when considering the factors shaping the regional gaps across Europe. It is well known that GDP fails as a measure of well-being and health. Given that health is multidimensional and the effective way to promote health and that reducing inequities in health means acting on their causes (social, economic, and environmental determinants), it becomes extremely important to involve all policy sectors and entities acting on these determinants. A more intersectoral and integrated approach-Health in All Policies-is needed in all phases, from planning the investments to their implementation.

Supplementary Materials: The following are available online at http://www.mdpi.com/1660-4601/17/5/1567/s1. Supplementary Material 1: CP fund allocation by intervention field dimensions and category of region. Figure S1: Allocation of funds by category of intervention across NUTS 2 level regions, 2014-2020. Supplementary Material 2: Less developed regions: priorities of investment and population health dimension addressed; Table S2: CP intervention fields by number of LD regions with planned investment and respective PHI dimensions addressed.

Author Contributions: Conceptualization, P.S.; methodology, P.S., Â.F., C.C., and I.S.; formal analysis, P.S., Â.F., C.C., and I.S.; investigation, P.S., Â.F., C.C., and I.S.; writing-original draft preparation, P.S., Â.F., I.S., and C.C.; writing - review and editing, P.S., Â.F., C.C., I.S., G.S., T.K., and E.P.; supervision, project administration, and funding acquisition, P.S. All authors have read and agreed to the published version of the manuscript.

Funding: This research was conducted under the EURO-HEALTHY project, which was funded by the EU's Horizon 2020 research and innovation program, Grant Agreement No 643398, and it received support from the Center of Studies in Geography and Spatial Planning (CEGOT), funded by national funds through the Foundation for Science and Technology (FCT) under the reference UID/GEO/04084/2019. Angela Freitas and Cláudia Costa are recipients of Individual Doctoral Fellowships funded by national funds through the Foundation for Science and Technology (FCT), under the references SFRH/BD/123091/2016 and SFRH/BD/132218/2017, respectively.

Acknowledgments: The authors would like to acknowledge the significant contribution and insightful comments made throughout the project by the Project Advisory Board members (Alec Morton, Patricia O'Campo, Pedro Pita Barros, and Anne Diez-Roux), who guaranteed the quality and success of the project. Special thanks are also extended to the panels of experts and stakeholders involved in the several participatory processes conducted to build the population health index.

Conflicts of Interest: The authors declare no potential conflicts of interest with respect to the research, authorship, and/or publication of this article.

\section{References}

1. Marmot, M. Fair society, healthy lives: The Marmot Review. Strategic review of health inequalities in England post-2010. Fair Soc. Heal. 2010, 126, S4-S10.

2. Borrell, C.; Mari-Dell'olmo, M.; Palencia, L.; Gotsens, M.; Burstrom, B.; Dominguez-Berjon, F.; Rodriguez-Sanz, M.; Dzurova, D.; Gandarillas, A.; Hoffmann, R.; et al. Socioeconomic inequalities in mortality in 16 European cities. Scand. J. Public Health 2014, 42, 245-254. [CrossRef] [PubMed]

3. European Commission. Health Inequalities in the EU. Final report of a Consortium Consortium Lead: Sir Michael Marmot; European Commission: Brussels, Belgium, 2013.

4. Santana, P.; Costa, C.; Freitas, Â.; Stefanik, I.; Quintal, C.; Bana e Costa, C.; Borrell, C.; Dimitroulopoulou, S.; Lopes Ferreira, P.; Krafft, T.; et al. Atlas of Population Health in European Union Regions; Santana, P., Ed.; Imprensa da Universidade de Coimbra: Coimbra, Portugal, 2017; ISBN 978-989-26-1462-5.

5. Solar, O.; Irwin, A. A Conceptual Framework for Action on the Social Determinants of Health. Social Determinants of Health Discussion Paper 2 (Policy and Practice); World Health Organization: Geneva, Switzerland, 2010.

6. Marmot, M. Achieving health equity: From root causes to fair outcomes. Lancet 2007, 370, 1153-1163. [CrossRef]

7. World Health Organization. Closing the Gap in a Generation; World Health Organization: Geneva, Switzerland, 2008. 
8. World Health Organization. Health in All Policies. Helsinki Statement Framework for Country Action; World Health Organization: Geneva, Switzerland, 2014; Volume 978.

9. World Health Organization. Proceedings of the Declaration of Alma-Ata International Conference on Primary Health Care, Alma-Ata, USSR, 6-12 September 1978.

10. World Health Organization. The Ottawa Charter for Health Promotion; World Health Organization: Geneva, Switzerland, 1986.

11. Busse, R.; Figueras, J.; Holland, W.; Le Grand, J.; Mckee, M.; Mossialos, E.; Belcher, P.; Moncrieff, S.; Albreht, T.; Anell, A.; et al. Measuring and tackling health inequalities across Europe. Eurohealth (Lond.) 2009, 60, 1089-1092.

12. Etches, V.; Frank, J.; Di Ruggiero, E.; Manuel, D. Measuring population health: A review of indicators. Annu. Rev. Public Health 2006, 27, 29-55. [CrossRef]

13. Kindig, D.; Stoddart, G. What is population health? Am. J. Public Health 2003, 93, 380-393. [CrossRef]

14. Braveman, P. What are Health Disparities and Health Equity? We Need to Be Clear. Public Health Rep. 2014, 129, 5-8. [CrossRef]

15. Scatigna, F. Deconstruction, Reconstruction: Time for a Europe of Regions. In The New European; UNITEE: Brussels, Belgium, 2014; Issue 2, pp. 27-29.

16. European Commission. Investments in Health. Policy Guide for the European Structural and Investments Funds (ESIF) 2014-2020.; European Commission: Brussels, Belgium, 2014.

17. Farole, T.; Rodríguez-Pose, A.; Storper, M. Cohesion policy in the European Union: Growth, geography, institutions. J. Common Mark. Stud. 2011, 49, 1089-1111. [CrossRef]

18. European Commission Regional policy. Making Europe's Regions and Cities More Competitive, Fostering Growth and Creating Jobs; European Commission: Brussels, Belgium, 2014.

19. Fratesi, U.; Wishlade, F.G. The impact of European Cohesion Policy in different contexts. Reg. Stud. 2017, 51, 817-821. [CrossRef]

20. Directorate-General for Regional and Urban Policy (European Commission). European Structural and Investment Funds 2014-2020: Official Texts and Commentaries; Publications Office of the European Union: Brussels, Belgium, 2016; ISBN 9789279394560.

21. European Commission. European Structural and Investments Funds 2014-2020: Official Text and Commentaries; European Commission: Brussels, Belgium, 2015.

22. Neagu, O.M.; Michelsen, K.; Watson, J.; Dowdeswell, B.; Brand, H. Addressing health inequalities by using Structural Funds. A question of opportunities. Health Policy (N. Y.) 2017, 121, 300-306. [CrossRef]

23. Benzeval, M.; Bond, L.; Campbell, M.; Egan, M.; Lorenc, T.; Petticrew, M.; Popham, F. How does money influence health? JRF Joseph Rowntree Found 2014, 70, 2167225.

24. Mackenbach, J.P.; Stirbu, I.; Roskam, A.-J.R.; Schaap, M.M.; Menvielle, G.; Leinsalu, M.; Kunst, A.E. Socioeconomic Inequalities in Health in 22 European Countries. N. Engl. J. Med. 2008, 358, 2468-2481. [CrossRef] [PubMed]

25. Santana, P.; Costa, C.; Marí-Dell'Olmo, M.; Gotsens, M.; Borrell, C. Mortality, material deprivation and urbanization: Exploring the social patterns of a metropolitan area. Int. J. Equity Health 2015, 14, 44. [CrossRef] [PubMed]

26. Nolasco, A.; Moncho, J.; Quesada, J.A.; Melchor, I.; Pereyra-Zamora, P.; Tamayo-Fonseca, N.; Martínez-Beneito, M.A.; Zurriaga, O.; Ballesta, M.; Daponte, A.; et al. Trends in socioeconomic inequalities in preventable mortality in urban areas of 33 Spanish cities, 1996-2007 (MEDEA project). Int. J. Equity Health 2015, 14, 33. [CrossRef] [PubMed]

27. Organization for Economic Cooperation and Development. How's Life in Your Region? Organization for Economic Cooperation and Development: New York, NY, USA, 2014; p. 295.

28. Rowlingson, K. Does income inequality cause health and social problems? Joseph Rowntree Found. 2011, $51,15970$.

29. Wilkinson, R.G.; Pickett, K.E. Income inequality and socioeconomic gradients in mortality. Am. J. Public Health 2008, 98, 699-704. [CrossRef]

30. Dahlgren, G.; Whitehead, M. European Strategies for Tackling Social Inequities in Health: Levelling up Part 2; World Health Organization: Geneva, Switzerland, 2006; pp. 6-7. 
31. Dahlgren, G.; Whitehead, M. Policies and Strategies to Promote Social Equity in Health. Stockh. Inst. Future Stud. 1991, 27, 4-41.

32. De Ruijter, A. EU Health Law \& Amp; Policy: The Expansion of EU Power in Public Health and Health Care; Oxford University Press: Oxford, UK, 2019; ISBN 9780198788096.

33. Cook, S.; Leppo, K.; Ollila, E.; Peña, S.; Wismar, M. Health in All Policies: Seizing Opportunities, Implementing Policies; Ministry of Social Affairs and Health: Helsinki, Finland, 2013; ISBN 9789520034061.

34. Santana, P.; Freitas, Â.; Stefanik, I.; Costa, C.; Oliveira, M.; Rodrigues, T.C.; Vieira, A.; Ferreira, P.L.; Borrell, C.; Dimitroulopoulou, S.; et al. Advancing tools to promote health equity across European Union regions: The EURO-HEALTHY project. Heal. Res. Policy Syst. 2020, 18, 18. [CrossRef]

35. Ferreira, P.L.; Tavares, A.I.; Quintal, C.; Santana, P. EU health systems classification: A new proposal from EURO-Healthy. BMC Health Serv. Res. 2018, 18, 511. [CrossRef]

36. Bana e Costa, C.; Oliveira, M.; Vieira, A. Decision support for multicriteria modelling of the population health index and evaluation, foresight and selection of policies. In Promoting Population Health and Equity in Europe: From Evidence to Policy; Santana, P., Ed.; Coimbra University Press: Coimbra, Portugal, 2017.

37. Bana e Costa, C.; Freitas, L.; Oliveira, M.; Rodrigues, T.; Vieira, A. Using the MACBETH socio-technical methodological approach to build the EURO-Healthy PHI. In Promoting Population Health and Equity in Europe: From Evidence to Policy; Santana, P., Ed.; Imprensa da Universidade de Coimbra: Coimbra, Portugal, 2017; pp. 71-77.

38. Freitas, Â.; Santana, P.; Oliveira, M.D.; Almendra, R.; Bana e Costa, J.C.; Bana e Costa, C.A. Indicators for evaluating European population health: A Delphi selection process. BMC Public Health 2018, 18, 557. [CrossRef]

39. Costa, C.; Freitas, Â.; Stefanik, I.; Krafft, T.; Pilot, E.; Morrison, J.; Santana, P. Evaluation of data availability on population health indicators at the regional level across the European Union. Popul. Health Metr. 2019, 17, 11. [CrossRef]

40. European Commission European Structural and Investment Funds (ESI Funds)-Explore Our Data. Available online: https://cohesiondata.ec.europa.eu/ (accessed on 18 June 2017).

41. Healy, J.D. Excess winter mortality in Europe: A cross country analysis identifying key risk factors. J. Epidemiol. Community Heal. 2003, 57, 784-789. [CrossRef]

42. Rechel, B.; Grundy, E.; Robine, J.-M.; Cylus, J.; Mackenbach, J.P.; Knai, C.; McKee, M. Ageing in the European Union. Lancet 2013, 381, 1312-1322. [CrossRef]

43. Kolkowska, E.; Soja, E. Attitudes towards ICT solutions for independent living among older adults in Sweden and Poland: A preliminary study. In Proceedings of the International Conference on ICT Management for Global Competitiveness and Economic Growth in Emerging Economies (ICTM), Wroclaw, Poland, 23-24 October 2017; Kowal, J., Kuzio, A., Makio, J., Paliwoda-Pekosz, G., Soja, P., Sonntag, R., Eds.; ICTM: Wroclaw, Poland; pp. 35-45.

44. Holford, J. Patterns of Lifelong Learning: Policy \& Amp; Practice in an Expanding EUROPE; Lit, LIT Verlag: Münster, Germany, 2008; ISBN 3825814483.

45. Hartlapp, M.; Schmid, G. Labour Market Policy for "Active Ageing" in Europe: Expanding the Options for Retirement Transitions. J. Soc. Policy 2008, 37, 409-431. [CrossRef]

46. Funding Health Care: Options for Europe; European Observatory on Health Care Systems Series; Mossialos, E.; Dixon, A.; Figueras, J.; Kutzin, J. (Eds.) Open University Press: London, UK, 2002; ISBN 0335209246.

47. Lavrijsen, J.; Nicaise, I. Social Inequalities in Early School Leaving: The Role of Educational Institutions and the Socioeconomic Context. Eur. Educ. 2015, 47, 295-310. [CrossRef]

48. European Parliament. Directorate General for Internal Policies. Policy Department B: Structural and Cohesion Policies. Education and Culture. Reducing Early School Leaving in the EU; European Parliament: Brussels, Belgium, 2011.

49. World Health Organization. Waste and Human Health: Evidence and Needs; World Health Organization: Geneva, Switzerland, 2016.

50. European Commission. Being Wise with Waste: The EU's Approach to Waste Management; European Commission: Brussels, Belgium, 2010.

51. Naik, K.S.; Stenstrom, M.K. Evidence of the influence of wastewater treatment on improved public health. Water Sci. Technol. 2012, 66, 644-652. [CrossRef] [PubMed] 
52. European Commission. Investing in Health, Commission Staff Working Document Social Investment Package; European Commission: Brussels, Belgium, 2013.

53. COCIR. COCIR Guide towards EU Structural and Investment Funds for Health Projects in 2014-2020; COCIR: Brussels, Belgium, 2014; Volume 66, pp. 644-652.

(C) 2020 by the authors. Licensee MDPI, Basel, Switzerland. This article is an open access article distributed under the terms and conditions of the Creative Commons Attribution (CC BY) license (http://creativecommons.org/licenses/by/4.0/). 